\title{
A New Architecture for monitoring Land use and land cover change based on remote sensing and GIS: A Data mining Approach
}

\author{
Younes Oubrahim ${ }^{1}$, Sara Lbazri ${ }^{1}$, Soumaya Ounacer ${ }^{1}$, Amina Rachik ${ }^{1}$, Reda Moulouki, Mohamed \\ Azzouazi $^{1}$ \\ ${ }^{1}$ Department of mathematics and computer science,Faculty of Science Ben Msik, Hassan II University
}

\begin{tabular}{ll} 
Article Info & ABSTRACT \\
\cline { 2 - 3 } Received Jul 18,2018 & $\begin{array}{l}\text { The issue of land use (LU) and land cover change (LCC) has become crucial } \\
\text { around the world in recent years, not only for researchers, but also for urban } \\
\text { planners and environmentalists who advocate sustainable land use in the } \\
\text { future. In Morocco, this phenomenon affects large areas and is all the more } \\
\text { pronounced because the climate is arid with cycles of increasing drought and } \\
\text { Soils are poor and highly vulnerable to erosion. In addition, the precarious }\end{array}$ \\
\hline Land use & $\begin{array}{l}\text { living conditions of rural populations pushes them to over exploit natural } \\
\text { resources to meet their growing needs, which further amplifies environmental } \\
\text { degradation. In this LU/LCC monitoring context, this paper aims on one hand }\end{array}$ \\
Gand cover change & $\begin{array}{l}\text { at giving a clear survey of classical methods and techniques used to monitor } \\
\text { SU/LCC, on other hand the authors propose a new architecture whose } \\
\text { Satellite imagery }\end{array}$ \\
objective is to integer data mining techniques to the LU/LCC monitoring in \\
order to automatically and efficiently improve the monitoring, control and \\
asset management in LU/LCC..
\end{tabular}

\section{Corresponding Author:}

FirstAuthor,

Department of Mathematics and Computer Science,

Faculty of Science Ben Msik, Hassan II University,

Av Driss El HartiSidiOthmane Casablanca B.P 7955, Maroc

Email: oubrahim.younes@gmail.com

\section{Introduction}

The difference between LU and LCC is not obvious (4). According to the Food and Agriculture Organization of the United Nations [1] Land cover is a physical description of space, defined as the physical bio-cover of the surface. There are several biophysical categories: vegetation (trees, bushes, fields ...), bare soil (even if it is a lack of cover), hard surfaces (rocks, buildings), wet surfaces and inland water bodies [1]. Land use characterizes the arrangements, activities and inputs introduced by man on a certain type of land use in order to obtain products and/or benefits from it, so we are talking about a description of land surfaces according to their socio-economic purposes: residential, industrial, commercial or agricultural areas [2]. Due to the implicit or explicit role of man in determining land use, it must be treated separately from land use. The study of land cover change and land use is interesting to focus on environmental issues in general. It is necessary to determine the nature and the mode of human's intervention that modify global land cover and land use patterns in response to changing needs [7]. The research and analyses carried out on land cover and land use form a necessary information base for the planners, the developers. At the international level, the topic of land use and land cover has been the subject of several research, programs and reports. One of the most important is the report presented by the scientific community of the LUCC international program "Land Use and Cover Changes" during the Open Science Meeting in January 1996 in Amsterdam. This program emphasizes the importance of an international effort to better understand the effects of soil management, as well as some impacts on the spatial and temporal variability of land use [10]. It also raises the problem of the scales to be adopted for such a problem, and indicates the importance of historical elements in the study of LU/LCC. In 
addition, research in this area facilitates sustainable land management and can be used as an example for planning, monitoring and evaluating the deployment of industrial activity [8].

Over the past few years, Remote sensing and Geographical Information System (GIS) have been proved to be a useful tool for many LU/LCC monitoring applications used to analyze the dynamics of land cover change [11], land cover classification, desertification identification [12], monitoring of land use changes, sand dune mapping and soil erosion modelling [6], water resource studies and surfacee typology by Radar [13]. However, choosing the best and efficient method or model remains one of the main challenges in the scientific literature. Classical GIS-based methods for modelling LU/LCC changes depend upon the utilization of deterministic conceptual descriptions joining spatio-temporal occurrences of the LU/LC changes and the geonatural settings in which they occur, inaccuracies and vulnerabilities in utilizing such models are unavoidable, for the most part because of the lack of precise spatio-temporal information of topographic and hydrologic factors. But also due to the simplistic modelling approach adopted in such deterministic description. These issues have led to the use of data mining algorithms to the modelling of desertification, landslide, erosion, topographic and other geo-natural mechanisms. These data mining methods may improve the accuracy in LU/LCC monitoring issues.

The rest of the paper is organized as follows: we begin Section 2 by an overview of remote sensing and Geographic information System (GIS) and their use for LU/LCC monitoring, after that we present related works, Section 4 is dedicated to the presentation of our proposed architecture, the final section is devoted to conclusion and future work.

\section{Remote sensing and gis for monitoring land cover change}

In this section, we will give an overview of remote sensing and GIS, their basic definitions,characteristics, and techniques applied to LU/LCC.

\subsection{Remote sensing and land cover}

Remote sensing is the science and the art of acquiring remotely the electromagnetic radiation emitted or reflected by a surface without direct contact with it. The solar radiation reflected by the earth's surfaces varies according to the nature and condition of the surfaces, but also according to the condition of the atmosphere, the environment of the surfaces, the lighting conditions or the characteristics of the sensor. Various sensors - embedded in vectors, most often aircraft or satellites, record it. In this regard the distance between the observed target and the platform plays an important role in determining the size of the observed region and the detail that can be obtained. A sensor placed on a platform far from the target may observe a larger area, but will not be able to provide much detail [18], the detail that can be discerned in an image depends on the spatial resolution of the sensor used. The spatial resolution depends on the size of the smallest element that can be detected. The spatial resolution of a sensor depends mainly on its resolution area or resolution cell and is a critical step in determining the maximum spatial resolution of the sensor. To be able to differentiate an element from the observed surface, the element in question must be equal to or larger than the resolution cell. If the element is smaller, it will generally not be differentiated since it is the average energy of the elements of the resolution cell that will be captured. However, under certain conditions, a smaller element can be detected if its reflexivity dominates that of the other elements present in the resolution cell. This is referred to as detection finer than resolution [9]. Three particular phases of the advancement of remote sensing are shown in Figure 1. 


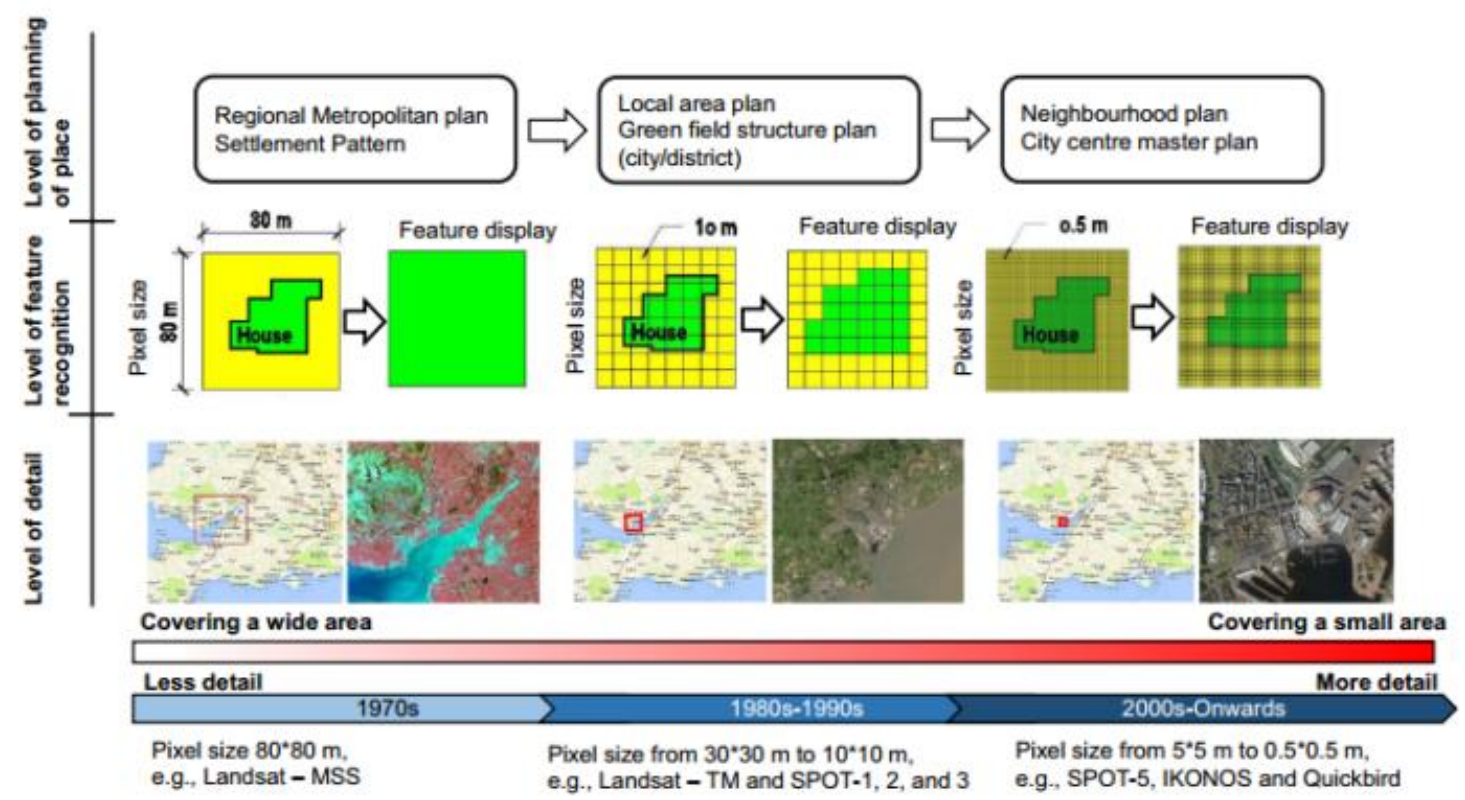

Figure 1.A comparaison of satellite generations

In general, satellites images can be characterized from three resolutions: spatial, spectral and temporal[19]. The relation between spatial, temporal and spectral resolution of satellite images is presented in Figure 2.

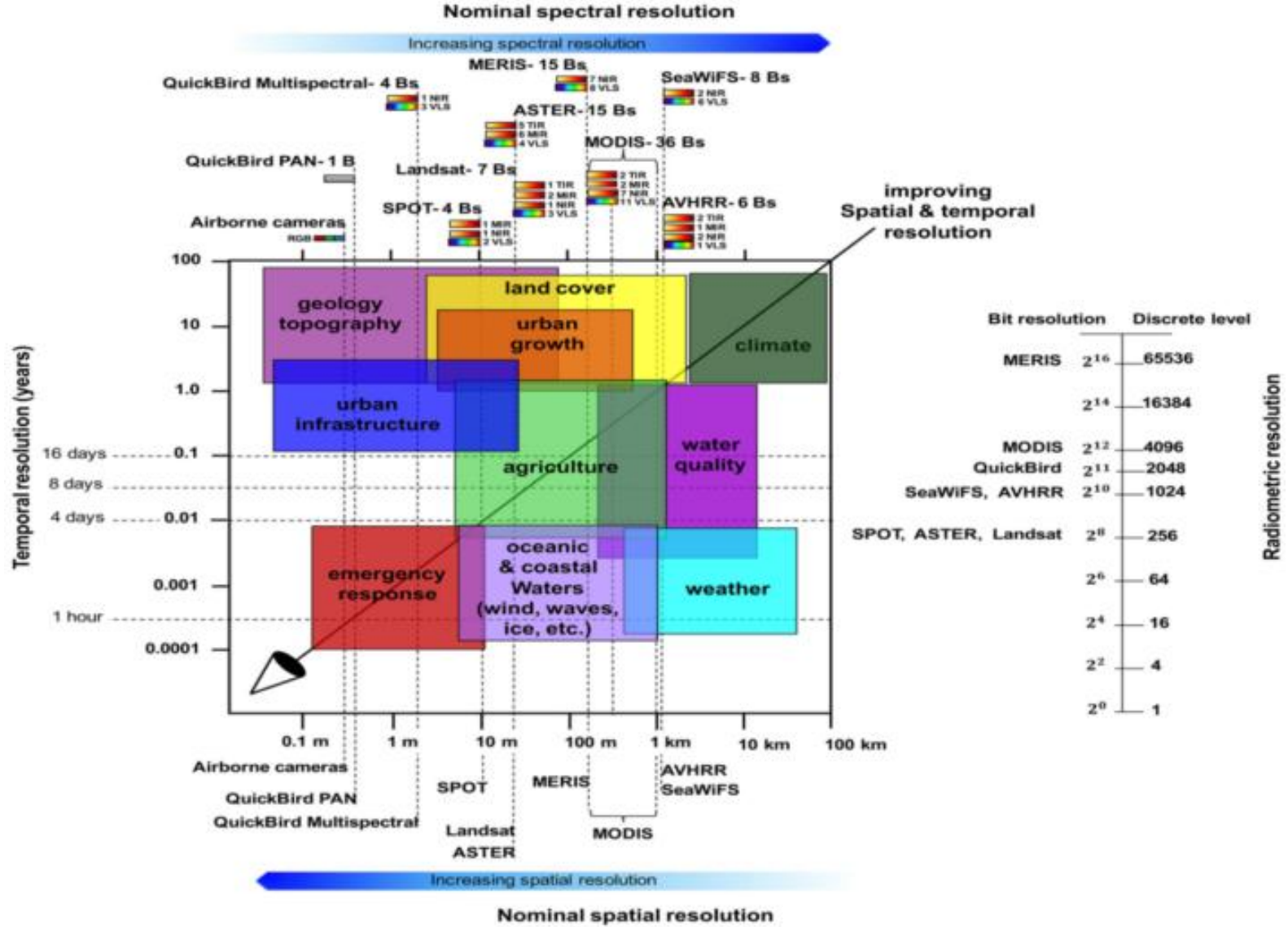

Figure 2. Relation of spatial, temporal and spectral resolution of satellite images (15)

- The spatial resolution of a sensor corresponds to the minimum size of the objects that he can see on the surface. It is defined as the power of separation on the surface of two adjacent objects. Therefore 
the precision of the discernible details on an image depends on the spatial resolution of the sensor used. (16].

- The spectral resolution is the ability of a sensor to distinguish two lengths of neighbouring waves. In addition, hyper-spectral sensors, which have a large number of sensitive channels are said to have a very high spectral resolution. [16].

- The temporal resolution is defined by the repetitiveness of the positioning of the sensor on the same place at the same time. [17].

Furthermore, whose characteristics often make satellite sensors specific to a given field of application. In this regards, the use of satellite images is limited to distinguishing, by comparing two images, the areas where changes have occurred from those that have not been affected by these changes [17]. However, this approach produces little information on the types of transitions between one land cover and use class and another, and is only interesting if one focuses on a given type of transition [18]. When considering environments with complex dynamics such as urban and peri-urban environments[20], it is necessary to favour a method that takes into account all the characteristics that make it possible to identify and characterize a given type of change[21], and that does not focus on a particular type of change, but considers all types of changes. The majority of commonly used methods for detecting changes have been developed to detect abrupt changes in land use from low to medium resolution remote sensing images using almost exclusively the spectral response of pixels [16].

\subsection{Geographic information system and Land cover change}

GIS enables us to establish complete links in the space of many types of information from varied sources, such as geography, geology, geomorphology, pedology, phytogeography, meteorology, usage analysis. On the ground, information is organized in data layers that can be

stored, interfered with, or isolated (Figure 3). The data can be organized in a raster or in a vector (polygon, polyline, and point). Digital imagery from remote sensing and scanned data, including the soil map, the hydrographic map, usually appear as a raster.

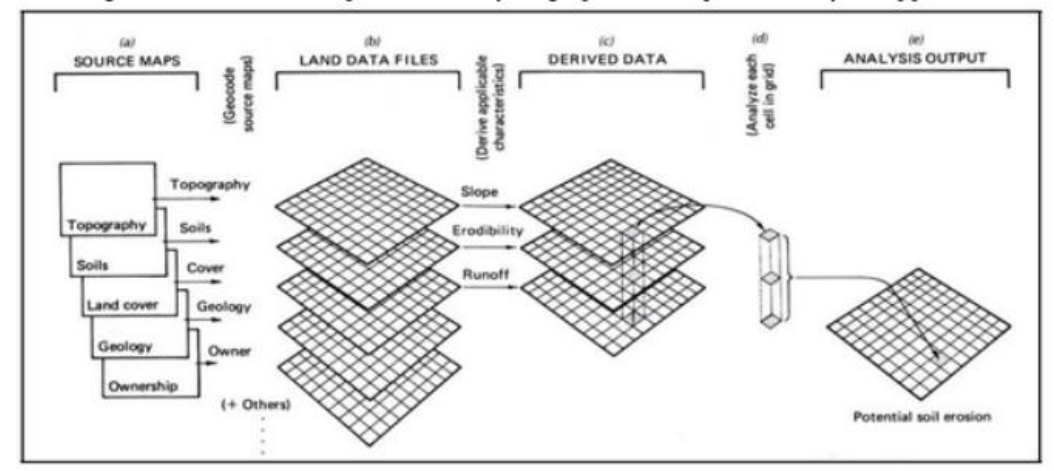

Figure 3. GIS and Process analyse (Lilles and Kiefer, 1994, 2000).

\section{Related works}

The coupled use of GIS and data mining techniques provide a powerful and efficient tool for monitoring land cover change and land use due to various factors. The monitoring is one of the methods essential for research in the land cover change[5]. In fact, monitoring must observe the dynamics of the environment, discern and measure its changes, integrating the spatial and temporal dimensions of its degradation. However, pointed out that measuring the degradation of soil is particularly difficult because there is a strong interaction between normal variability or random rainfall and anthropogenic changes in vegetation cover[7]. Therefore, surveillance is in depth research in which any factor leading to misunderstanding must be taken into account[8], used satellite data to identify and monitor various types of environmental changes such as urban development or urban fringe development, forest change, deforestation, coastalmodification, change land use in agriculture. Some research on remote sensing applied to arid zones[10][11][13][14], are particularly noteworthy Those researchs has both concerned the monitoring of main phenomena such as surface albedo mutation, surface albedo desertification, land-use change, ecosystem degradation, and modelling of human- 
environment interaction, they were based on treatment results of remote sensing. One of the limitations of such monitoring LU/LCC approach is the fact that the priority is not given to determine the influential factors. Or the need for an approach based on hybrid data mining algorithms.

\section{Proposed Architecture}

In the field of LU/LCC monitoring, satellite images are a valuable data source for monitoring changes in occupancy and use of natural or anthropogenic soils and assess their impacts. These changes are characterized by a wide variety of intensities, rhythms and forms, ranging from sudden mutations with a large spatial influence generated for example by natural disasters to subtle and regular changes affecting small areas. Therefore, identifying the efficient rating of various parameters and indices including topographic (elevation, aspect, slope degree, aspect, and normalized difference vegetation index), hydrologic (distance from river and drainage density), socio-economic (population index pressure, distance from roads, distance from river) enables deciders and environmentalists planners to apply the adequate intervention or the suitable measures to achieve improvement in LU/LCC monitoring. In this respect, there are a wide variety of popular current techniques within Geospatial big data analytics.

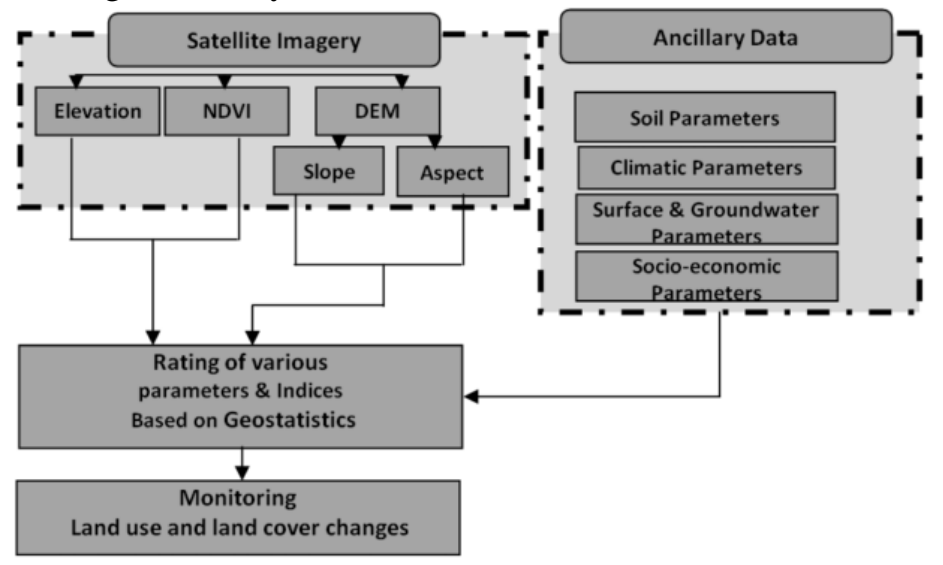

Figure 4. Classical Flow chart for monitoring Land use /Land cover change

Most used techniques are GIS-based. Figure 4 depicts the classical Flow chart for LU/LCC monitoring. From a glance we can see that the process requires three major levels, beginning with data storage level and ending with Visualization level. The data storage level is composed from remote sensing images which include generally topographic satellite images, hydrologic satellite images and images reprensenting the human activities in the concerned area. The other data source is ancillary data including soil data, climatic data, surface data and socio-econ omic data. 


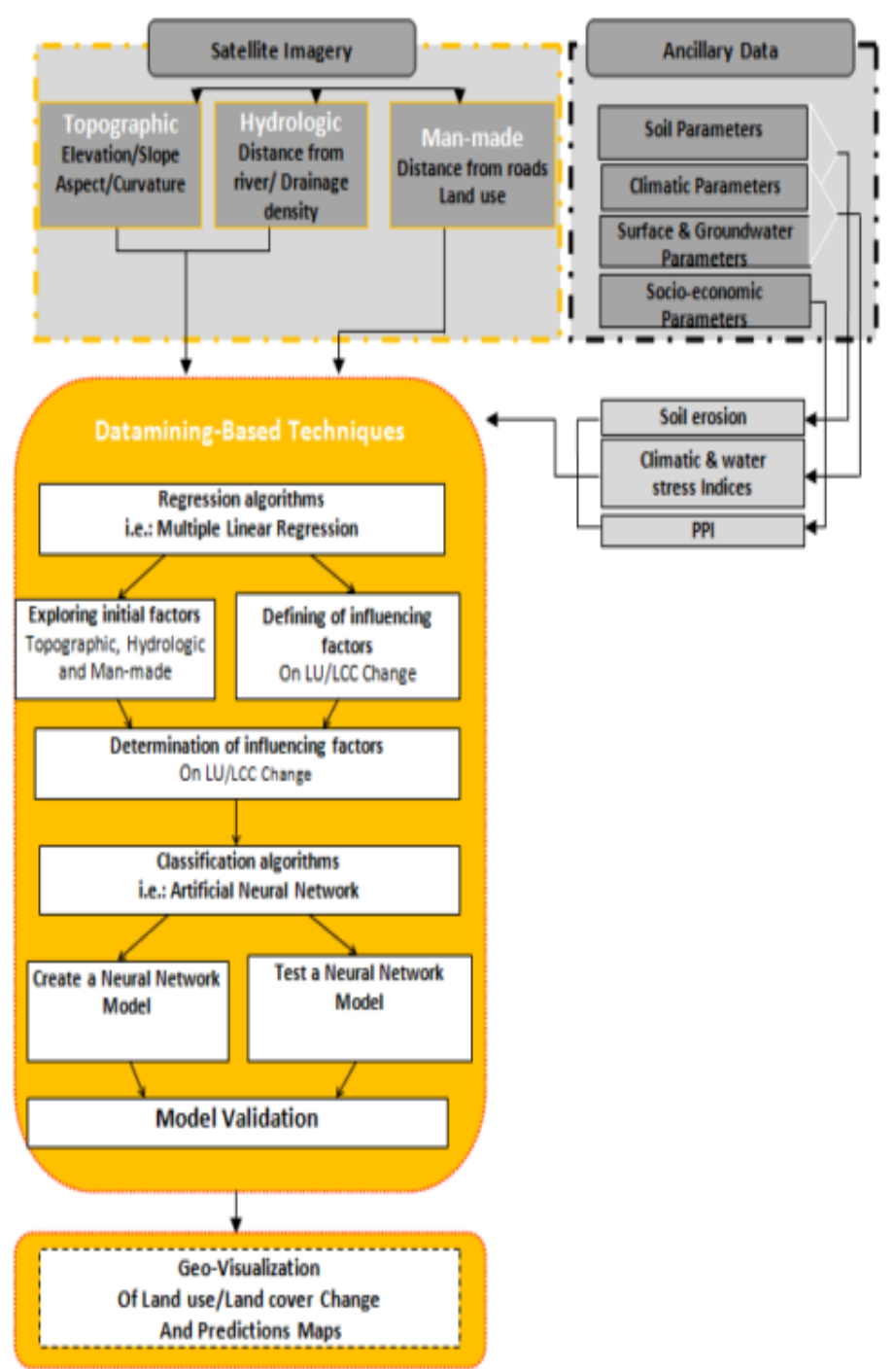

Figure 5. Proposed Flow chart for monitoring Land use /Land cover change

One of the limitations of such monitoring land cover/land use implementation system is the factthat the rating of various parameters and factors is achieved by GIS-based modelling, without taking inconsideration the Weightages allocation of every factor. Furthermore some of parameters are not mutually exclusive and are correlated with each other. In order to cope with this pitfall in the classical LU/LCCmonitoring method, there is a need for a hybrid method that takes into consideration the particularities of each parameter and factor. Figure 5 is an illustration of the proposed monitoring land cover/land use flowchart. The main objective of the proposed flow chart is to detect LU/LC changes, using data miningtechniques to link heterogeneous data such as topographic and hydrologic from satellite images. Thisproposed flow chart aims to propose a relevant alternative approach to define a monitoring mechanismbased on multi-source satellite images (spectral, textural and temporal), environmental data and socioeconomicdata. 


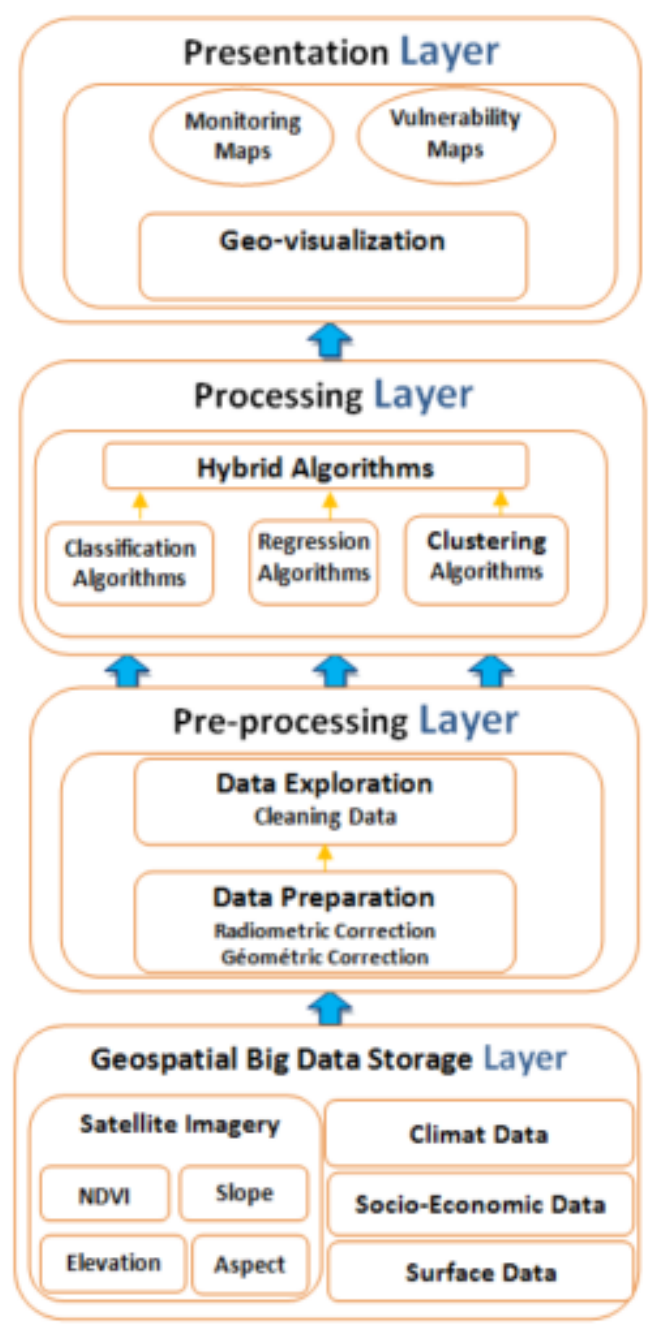

Figure 6: Proposed Architecture for monitoring Land use /Land cover changes

As shown in Figure 6, the major components of the proposed architecture for monitoring LC/LCCare geosptial big data storage layer, Pre-processing layer, processing layer, presentation layer. The firststep is to select only the potentially relevant data. In this regards, Satellite Imagery including topographicdata, hydrologic data, climate data, socio-economic data, surface data are selected, on which a preprocessingphase is carried out, the preprocessing phase is composed of two main operations, the first

operation is the radiometric and geometric correction for all topographic and hydrologic satellite images.Then, the obtained data go through a formatting phase, in order to prepare them for the Data miningprocess. Finally, the last step is a step of analysis and interpretation of the knowledgeextracted by datamining, to make it readable and understandable by the user. The various needs require differentapproaches such as that classification, regression, clustering and association rules.

\section{Conclusion and Futur work}

LU/LCC is one of the main criteria to be considered in the implementation of decisions based on the concept of sustainable development of theenvironment, whether at the global, regional or local level. Inthis context, remote sensing and GIS tools can beeffectively used in order to assess and monitorLU/LCC. However classical GIS-based methods for modelling LU/LCC depend upon the utilization ofdeterministic conceptual descriptions joining spatio-temporal occurrences of the LU/LCC and the geoenvironmentalsettings in which they occur, 
inaccuracies and vulnerabilities in utilizing such models are unavoidable, for the most part because of the lack of precise spatio-temporal information of topographicand hydrologic factors. But also to the simplistic modelling approach adopted in such deterministicdescription. In this paper, we have proposed an architecture for monitoring LU/LCC, which is based onsatellite data, GIS and data mining techniques. Therefore, the proposed architecture is able to benefit fromthe power of data mining algorithms in term of enhancing accuracy of the monitoring LU/LC changes.Future development consist on the use of Multiple Linear Regression algorithm to determine the mostinfluencing factors on desertification in southwest of Morocco based on spatio-temporal satellite imagesand ancillary data, next we implement the Neural Network algorithm for predicting desertification areasin this zone.

\section{References}

[1] Di Gregorio A. Land cover classification system: Classification concepts and user manual,LCCS. Rome: FAO Publishing Management Service; 2005

[2]Aspinal RJ, Hill MJ (eds). Land use change: science, policy and management. Boca Raton: CRC Press; 2008.

[3]Feranec J, Hazeu G, Christensen S et al. Corine land cover change detection in Europe (case studies of the Netherlands and Sl ovakia). Land Use Policy; 24(1); p.234-247 ; 2007

[4]Dimyati, M., Mizuno, K., Kitamura, T., 1996. An analysis of land use/cover change using thecombination of MSS Landsat and land use map: a case study in Yogyakarta, Indonesia. Inter. J. Rem.Sen. 17, 931-944.

[5]Ruiz-Luna, A., Berlanga-Robles, C.A., 2003. Land use, land cover changes and costal lagoon surface reduction associated with urban growth in northwest Mexico. Land. Ecol. 18, 159171.

[6]Ottichilo.W.K "Use of space technology in disaster risk assessment and monitoring," in Proc. Second International Conference on Early Warning (EWC-II), Bonn, Germany, 2003.

[7]Turner, M.G., Ruscher, C.L., 2004. Change in landscape patterns in Georgia. USA Land. Ecol. 1 (4), 251-421. Association for the Study of Liver Diseases, 2016.

[8]Yuan, F., Sawaya, K.E., Loeffelholz, B.C., Bauer, M.E., 2005b. Land cover classification and change analysis of the twin cities (Minnesota) metropolitan area by multi-temporal Landsat remote sensing.Rem. Sens. Envi. 98, 317-328.

[9]Curran PJ Principles of remote sensing. Longman Inc, London, (1985).

[10]Warren and J. K. Maizels, "Ecological change and desertification," in Proc. Secretariat of United NationsConference on Desertification: Its Causes and Consequences, Oxford: Pergamon Press, 1977.

[11]Selcuk, R., Nisanci, R., Uzun, B., Yalcin, A., Inan, H., Yomralioglu, T., 2003. Monitoring landuse changes by GIS and remote sensing techniques: case study of Trabzon, http://www.fig.net/pub/morocco/proceedings/TS18/TS18_6_reis_el_al.pdf 5.

[12]M. V. Khire and Y. Y. AgarwadkarQualitative Analysis of Extent and Severity of Desertification for Semi-Arid Regions Using Remote Sensing Techniques, International Journal of Environmental Science and Development, Vol. 5, No. 3, June 2014

[13]J. E. M. Baartman, G. W. J. van Lunden, M. S. Reed, C. J. Ritsema, and R. Hessel, "Desertification and land degradation: origins, processes and solutions," Desire Report Series, ISRIC, Netherlands, no. 4, November 2007.

[14]Fischer, W.A.; Hemphill, W.R.; Kover, A. Progress in remote sensing (1972-1976). Photogrammetria 1976, 32, 33-72.

[15]Kadhim, N.; Mourshed, M.; Bray, M. Advances in remote sensing applications for urban sustainability. Euro-Mediterr. J. Environ. Integr. 2016, 1, 7.

[16]Robin,. La télédétection : des satellites aux SIG, Paris, Nathan, 320 p. 1995

[17]J. Inglada et G. Mercier. A New Statistical Similarity Measure for Change Detection in MultitemporalSAR Images and Its Extension to Multiscale Change Analysis. IEEE Transactions on Geoscience and Remote Sensing, vol. 45, pages 1432-1445, 2007. 1, 38, 41. 
[18]Ok.AO. Automated detection of buildings from single VHR multispectral images using shadow information and graph cuts. ISPRS J Photogr Remote Sens 86:21-40, 201.

[19] Md. Haidar Sharif, Sahin Uyaver, and Zaid Zerdo, Periodicals of Engineering and Natural Sciences Vol. 6, No. 1, April 2018, pp. 84 - 94

[20] Aruna Flarence, Srikanth Bethu, V Sowmya, Kollu Anusha, B Sankara Babu eriodicals of Engineering and Natural Sciences. Vol.6, No.1, June 2018, pp. 201-214

[21] Hande Sanem ÇINAR1, Nebahat Nihan PARLAK1, Nazlı YILDIZ DÖNMEZPeriodicals of Engineering and Natural Sciences ISSN 2303-4521 Vol.6, No.2, December 2018, pp. 159167. 